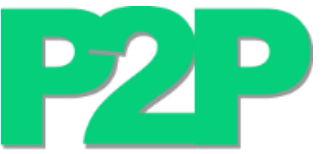

INOVAÇÃo
ARTIGO

DOI: https://doi.org/10.21721/p2p.2018v5n1.p88-106

\title{
JUSTA TRAMA, ELOS SOLIDÁRIOS
}

Nelsa Inês Fabian Nespolo ${ }^{1}$

Cooperativa Central Justa Trama

e-mail

\section{Resumo}

O trabalho tem por objetivo apresentar a iniciativa da rede de cooperação solidária: Justa Trama, o processo de construção da marca e o compromisso com o desenvolvimento de seus apoiadores. Aborda as relações entre os elos dessa cadeia bem como sua representação na comercialização de seus produtos.

Palavras-chave: Complexos Cooperativos; Economia solidária, Cooperativismo.

\section{FAIR TRAMA, THE SOLIDARIES}

\begin{abstract}
The purpose of this paper is to present the initiative of the Solidarity Cooperation Network: Justa Trama, the brand building process and the commitment to the development of its supporters. It addresses the relationships between the links in this chain as well as its representation in the marketing of its products.
\end{abstract}

Keywords: Cooperative organizations; Solidarity economy; Cooperatives.

${ }^{1}$ Costureira; Diretora presidente da Cooperativa Univens; Cooperativa Central Justa Trama, Vice-presidente da Unisol Brasil. Autora do livro Tramando Certezas e Esperanças, 2014.

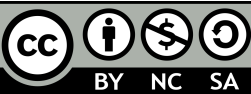

P2P \& INOVAÇÃO, Rio de Janeiro, v. 5 n. 1, Ed. Especial, p.88-106, 2018. 


\section{A JUSTA TRAMA}

Até 2003 vários ensaios foram feitos para criar uma articulação entre os vários elos da cadeia têxtil, porém na sua maioria sem continuidade, muito mais motivados por técnicos e assessores do que por incorporação das cooperativas e associações. Neste período estava a CONES (Cooperativa Nova Esperança S. P) ADS (Agência de Desenvolvimento Solidário (ADS) da CUT- Central Única dos Trabalhadores) e o Esplar. Mais tarde a Textilcooper Cooperativa de Tecelagem e a Univens (Cooperativa de Costureiras Unidas Venceremos do R.S). Neste período a ADS (2002, p. 44), elaborou textos sobre os complexos cooperativos e na área têxtil estava fazendo demonstrativos de como isso poderia concretamente acontecer. $\mathrm{O}$ texto, bastante motivador, diz: “O principal objetivo deste projeto é promover articulação entre os atores de diferentes segmentos da cadeia produtiva têxtil visando a produção de têxteis orgânicos de algodão, respeitando os princípios do comércio solidário”. E seguindo faz uma análise de cada etapa do processo produtivo, e de cada ator possivelmente envolvido.

Em outubro de 2003 houve um intercâmbio em Barcelona, organizado pela Unisol São Paulo, patrocinado pela Fesalc da Espanha e a prefeitura de Badalona.

A Unisol São Paulo proporcionou a participação de duas cooperativas que fariam parte da construção da cadeia: Univens e Cones. O mais importante é que neste intercâmbio tive acesso ao material da ADS e voltei extremamente convencida de que esta articulação deveria acontecer.

No início de 2004 em reunião da ADS, foi quando paralelamente houve a reunião do maior número de representações: TextilCooper, Univens, Esplar, CONES e apoiadores como Eli e Egeu. E começamos a enfrentar todas as dificuldades. A primeira era que a Textilcooper precisaria de um tear para poder tecer a malha. E para isso o então Deputado Federal Paulo Pimenta abriu uma agenda no gabinete do Ministro do Trabalho Berzoini, do Governo Lula.

O chefe de gabinete nos atendeu (Nelsa e Egeu), apresentamos todos os números e significados e achou que era um bom projeto e assim através da Fundação Banco do Brasil financiou o tear circular, projeto feito pela ADS para ser instalado na Textilcooper. Com certeza uma grandiosa conquista. Agora já poderíamos ter malha, moletom.

O que neste período era mais difícil, era enfrentar a afirmação de que este projeto era para o futuro, esse futuro significava pelo menos 5 anos, e não queríamos e nem poderíamos aceitar esta espera. 
No R.S vários grupos e cooperativas se animavam com a ideia e possibilidades. No Fórum Brasileiro de Economia Solidária isso também vai para o debate. E assim mais dois novos componentes se animaram e aproximaram para esta discussão promovida pela Univens: a Fio Nobre de S.C, na época uma empresa familiar solidária que produzia cordões e fitas para calçados e fazia roupas de tricô e também produção com teares manuais; e a cooperativa Açaí - R.O uma cooperativa de artesãos, que com o beneficiamento de sementes produzindo também botões, articularia a Amazônia e de lá viria nossas tintas naturais.

Em final de julho de 2004 fundamos a Unisol/Brasil, num momento onde a economia solidária cresce muito, tanto em números como também em vários setores pelo Brasil afora, e víamos também que com certeza seria um espaço especial para a construção desta cadeia.

Agora temos nossa central de representação, fazemos parte também da direção executiva. Tem um significado especial para a luta de economia solidária e fortalecimento dos empreendimentos, sermos os empreendimentos e ao mesmo tempo os que dirigem uma entidade que fala pelos empreendimentos. Tudo muito novo e desafiador.

Em setembro do mesmo ano (2004) o FBES (Fórum Brasileiro de Economia Solidária) organiza o $1^{\circ}$ encontro nacional de empreendimentos da Economia Solidária e proporciona encontros por setores e isso anima mais ainda a criação realmente desta cadeia.

E já estávamos em clima para o $5^{\circ}$ Fórum Social Mundial que aconteceria em janeiro de 2005 em Porto Alegre.

Nos primeiros dias de dezembro de 2004, reuníamos em São Paulo: Univens, Fio Nobre, Textilcooper e CONES além de assessores da ADS e Unisol. Queríamos fazer algo bem concreto, fazer a primeira compra da ADEC que estava com 1 tonelada e meia de algodão e termos os primeiros produtos no Fórum Social Mundial.

A reunião foi tensa, difícil não conseguimos financiamento e saímos bastante fragilizados. A Cones desanimada porque era mais uma das tantas reuniões que não concretizava nada na prática, e só apareciam empecilhos, na verdade havia agora o algodão, mas não tínhamos fontes de financiamento para adquirirmos esse algodão, já que todos tínhamos dificuldade financeiras.

Decidimos então que iríamos encarar as 60 mil sacolas do FSM como uma grande prova de nossas capacidades. A Univens coordenou a produção e a negociação com mais 35 empreendimentos de costura e mais 2 de fiação e tecelagem.

Foi um grande aprendizado, por que neste processo conseguimos que a confecção agregasse valor, ou seja, as costureiras ganharam o dobro por produzir esta sacola, além de todo o crescimento político de ver seu fruto percorrer o mundo. Contudo, o FSM pagou 
menos que no Fórum Social Mundial de 2004. Nossa sacola havia custado R $\$ 4,50$. Foi um período curto onde todos cresceram, pois teve empreendimentos que fizeram todo o processo, corte, costura e confecção, outros só faziam uma parte e isso também ajudou a solidariedade e compromisso. Houve quem teve que refazer o trabalho e que foi compreendido pelos demais; seu depoimento nos emocionou a todos pelas demonstrações do que realmente estamos construindo, e que podemos dentro desta sociedade capitalista, estabelecer entre os trabalhadores valores e princípios fundamentais que também viabilizam a própria produção.

Foi uma grande história e não poderia mais termos nenhuma dúvida sobre nossa capacidade e potencialidades.

No FSM em janeiro de 2005, nos encontramos todos: Univens, Açaí, Fio Nobre, têxtil Cooper e Adec, só não foi possível a CONES, e fizemos nossa oficina com depoimento de cada um dos elos e mais o presidente da UNISOL, Cláudio (Metalcoop). Estávamos lá, lançando e decidindo nosso futuro, o que iríamos produzir, foi o primeiro momento em que participou além do Esplar também a Adec, (os agricultores), onde decidimos priorizar alguns produtos: camisetas, sacolas, bermudas, calças, cangas, batas entre outros.

Cada um dos elos ia na frente de todos e explicava com baner, amostras ou cartaz, o que o empreendimento produzia. Não havia muita gente na oficina, ela coincidiu com a vinda do Presidente Lula no FSM, mas para nós foi marcante, foi como o lançamento oficial desta construção.

Durante o FSM, Loide da Têxtil e Nelsa da Univens procuraram a SENAES (Secretaria Nacional de Economia Solidária) com Sônia Kruppa e Fábio Sanches para a possibilidade de financiar a primeira produção, foi nos dado o sinal positivo e começamos a elaboração do projeto que foi concluído por Egeu no valor de $\mathrm{R} \$ 108.000,00$ em nome da Cooperativa Univens. Como o recurso demorou, a Unisol e o Sindicato dos Metalúrgicos de Porto Alegre anteciparam um valor como empréstimo e assim fizemos a compra de 1,5 toneladas da ADEC.

Iniciamos todo o processo de construção da marca junto com a agência "Lavoro" e foi outro momento marcante: atuação muito forte da Univens com a Fio Nobre, neste momento sem recurso, muito mais por sonhos e dedicando-se gratuitamente pois agora estávamos determinados nessa Construção. Idalina se desloca para o RS, quase uma aventura, ficando na beira da estrada na Freeway com a solidariedade de motoristas até chegar na Univens, e avançávamos junto no debate. Reuniões ao sábado, a Univens parando a produção para pensar juntos nomes: Algodão Doce, Algodoaria, Algodão Brasileiro entre outros nomes. 
O nome que ia afinando era Algodão Brasileiro, mas para todos que contávamos, diziam que o nome não convencia e alguns de nós achávamos que nos limitava ao território brasileiro.

Eliminamos todos por voto e outros estavam eliminados porque já existiam como Marca. Mas a última sugestão veio por e-mail de Egeu e Cris (Coop. Versus) que na verdade eram duas sugestões: Justa Trama ou Trama Justa. E isso soou no ouvido e no coração de todos como expressão do que queríamos: Construir uma Justa Trama. E o nome já diria tudo por si só. Pois seria nossa trama, e tramado de fios.

Como não foi possível lançar no FSM, decidimos que lançaríamos em novembro no Fórum Mundial do Turismo no Rio de Janeiro. E precisávamos correr contra o tempo.

Para definir o estilo de roupas, fizemos uma oficina Univens/Fio Nobre e apresentamos o que cada um tinha, foi um período onde as sócias criavam e apresentavam idéias, e assim chegávamos a primeira produção que foram: Camisetas (Regatas e Baby loock), ciganas, bermudas, calças, corsário, bolsas, batas de tecido tipo pólo, batas femininas, blusas de tricô, bolsas de tear, saia de malha de babado. Imprimimos as estampas de alguns animais típicos e outros em extinção, como: Mico-leão, abelha, borboleta, golfinho, arara...

Mesmo sentindo que faltaria algo que desse mais vida, esse era nosso primeiro lançamento, algo nunca vivido antes por nós. Havia para o Rio de Janeiro uma expectativa de um desfile em Copacabana como parte da abertura do Fórum Mundial do Turismo e também com a participação de artistas. No andar de tudo por um desentendimento do Governo Estadual do RJ com o municipal e mais desarticulação interna da Economia Solidária local, não foi possível. Nada aconteceu do que havia sido previsto.

Organizamos um ônibus que saiu de POA com sócios da Univens, passou por SC com a Fio Nobre, e em SP com os outros sócios da CONES e Têxtil Cooper. Enquanto o pessoal viajava para o evento, acontecia a reunião da articulação: Univens (Nelsa, Isaurina e Rodrigo), Textilcooper (Loide e Antonio), Fio Nobre (Márcia e Idalina), Esplar (Pedro Jorge), Adec (Dario), Coop. Açaí (Dalvani) Cris, Egeu, Denise e Aroldo da Senae. Colocamos as peças no meio da sala, e começamos a tratar de valores, composição de preços, o que compreendia cada etapa. Dário da Adec defendeu que deveríamos buscar valores justos que tornassem o projeto sustentável e ao mesmo tempo que quem produz pudesse adquirir.

Foi um dos momentos que mais houve crescimento coletivo e que realmente pudemos viver o que é um comércio justo. No final agregamos valor a todos os elos e colocamos mais um valor que geraria um fundo para sustentar todo o processo de produção, e cada um ao seu tempo, pois os agricultores do Ceará plantam em março, colhem em junho/julho, a fiação e 
tecelagem vai até o final do ano. Ou seja, até chegar as vendas é praticamente 1 ano e não é possível aguardar esse tempo para cada elo receber.

Mas também decidimos dois valores diferenciados: valor para quem vende de $10 \% \mathrm{e}$ valor para sócios diretos de $20 \%$ a menos. É importante que os sócios sejam os primeiros a usar este produto e que a venda e as feiras motivem.

Outro aspecto importante foi a embalagem, não poderíamos entregar um produto ecológico em uma sacola de saquinho plástico, então decidimos pela sacola de papel tipo craft, que além de contar quem somos também chama para o compromisso com o meio ambiente.

E o lançamento do RJ? Acabou acontecendo na favela do Cantagalo, no espaço Criança Esperança, sem nenhuma divulgação, as crianças, adolescentes e os pais que lá estavam além de comunidades da Economia Solidária local assistiram ao desfile realizado pelas meninas da comunidade do Rio de Janeiro, além do desfile fizemos uma fala de cada elo da cadeia. Não deixamos a peteca cair, as meninas do desfile estavam muito lindas, nos animou muito e enfim este foi o marco de nosso lançamento. Os cooperados sócios que foram estavam fascinados pelo RJ e, portanto, todos saíram bastante animados.

Estava assim lançada a cadeia do algodão ecológico Justa Trama para o Brasil e para o Mundo; e isso, mesmo que tenha acontecido entre nós, nos parecia muito.

Associação de Desenvolvimento Educacional e Cultural de Tauá - ADEC, A ADEC foi fundada em 1986, no município de Tauá (CE) por iniciativa de grupos de mulheres artesãs e em 1993 redirecionou suas atividades para a Agricultura Familiar, organizando a produção agroecológica de algodão, milho, feijão, gergelim e nim, contando com aproximadamente 150 agricultores.

Cooperativa Nova Esperança - CONES, localizada no município de Nova Odessa (SP). Empresa recuperada pelos trabalhadores, a CONES é composta por 320 trabalhadores que realizam a fiação do algodão. Compunha o segundo elo da cadeia produtiva na produção e fornecimento dos fios agroecológicos para a produção de tecidos e malha.

Cooperativa Têxtil de Sto. André - Textilcooper, localizada no município de Sto. André (SP), a cooperativa foi uma empresa recuperada, que produziu em maior quantidade cobertores, tem em torno de 90 trabalhadores. Participou ativamente nos fóruns de economia solidária e na Unisol Brasil. Tecia e nos fornecia o tecido e a malha.

Cooperativa de Trabalho dos Artesãos do Estado de Rondônia - AÇAI, localizada em Porto Velho (RO), é composta então por 100 associados, sendo que cada um destes com produtos e técnicas diferenciadas. Os principais produtos são: reciclagem, trabalhos em 
cestaria, madeira, coco, marchetaria, sementes, entre outras. Trabalha também com as sementes transformando-as em colares, pulseiras, brincos, cintos e outros acessórios. Além de participar dos Fóruns Municipal, Estadual e Brasileiro de Economia Solidária, a Cooperativa Açaí desenvolve importante trabalho social junto a mulheres detentas. É a responsável pela quinta etapa do processo produtivo.

Cooperativa de Costureiras Unidas Venceremos - UNIVENS, localizada em Porto Alegre (RS) foi fundada em maio de 1996, por mulheres, entre 18 e 70 anos, que resolveram formar a Cooperativa para enfrentarem o desemprego e a expulsão do mercado de trabalho. Tem 23 associadas, agregando os serviços de serigrafia ao da costura, personalizando assim qualquer tipo de produto. Participa ativamente do Fórum Municipal, Estadual e Brasileiro de Economia Solidária e a Unisol Brasil. Integra o quarto elo da cadeia produtiva confeccionando peças masculinas e femininas em escala, tais como camisetas, calças, jaquetas, vestidos, moletons.

FIO NOBRE, localizada no município de Itajaí (SC), então uma microempresa solidária, no modelo associativo, que já estava no mercado há 12 anos participando ativamente dos Fóruns Municipal, Estadual e Brasileiro de Economia Solidária. Formada por 9 associados que produzem cordões e fios diversos para o ramo calçadista, confecção e roupas artesanais. Compõem o quarto elo da cadeia produtiva com desenvolvimento do design e confecção das roupas em tecido com detalhes artesanais, peças em tricô e bolsas em tear.

Já estávamos na segunda produção em 2006 com 2 toneladas e meia de algodão, pois é referente a colheita de 2005. Essa foi a última produção feita pela Textilcooper, pois no final de 2006 fecha-se a Cooperativa por motivos financeiros e de gestão, realmente não conseguiu mais dar continuidade. A Justa Trama não daria viabilidade por que ainda tínhamos uma produção muito pequena de algodão.

A Justa Trama vai ficando conhecida pela participação das várias feiras a nível nacional, e sempre participa com um desfile bem peculiar. As pessoas que desfilam são altas, baixas, brancos, negros, homens, mulheres, gordos, magros. É o povo da Economia Solidária assumindo sua própria marca.

Ampliamos para novos produtos como vestidos, jaquetas, calças femininas, cangas diversas. Em 2006 elaboramos um novo projeto através da Unisol para SENAES e Fundação Banco do Brasil para equipar melhor todos os elos. Projeto que só acontece de fato em 2008 e conclui-se em 2009.

Acontecimento muito importante em julho de 2006: o programa Globo Repórter (Globo), apresenta a construção da cadeia do algodão como uma das iniciativas que demonstram a capacidade sem limite dos trabalhadores, é um grande momento pois lança a 
cadeia para os meios de comunicação. Mesmo sem aparecer a marca, é uma grande conquista estar no horário nobre em cadeia nacional.

Mas em 2006 participamos do encontro Ibero-Americano de cooperativismo na Venezuela, nós e mais uma grande delegação do Brasil, junto com todos os países da América Latina e Central, além de Espanha e Portugal.

Depois deste evento fomos convidados pelo governo de Hugo Chaves, pelo Ministério do Desenvolvimento a uma visita. Fomos: Dalvani, Chagas, Idalina, Ronildo, Loide, Nelsa, Cones e Allan Dias.

Durante 10 dias estivemos na Venezuela para desenvolver com os diversos elos a perspectiva da construção da cadeia de algodão de lá. Momento bastante marcante e por causa deste evento ficamos juntos por todos esses dias.

$\mathrm{Na}$ Venezuela percorremos os vários elos da cadeia, fomos super bem recebidos e recepcionados em cada local, contávamos nossa história 2 vezes por dia a grupos diferentes, Léo, representante do governo, nos acompanhou permanentemente, deitávamos tarde e acordávamos bastante cedo como o dia que voltamos de São Cristóvão era mais de $2 \mathrm{~h}$ da manhã e 6h já estávamos saindo para a nova etapa.

O governo havia transformado o que aqui seria o nosso "SENAI" em um grande articulador e formador de cooperativas, formação profissional, e formação política, todos se apropriavam da história do País, e dos princípios socialistas BOLIVARIANOS defendidos pelo governo, conheceriam profundamente os mártires e lutadores da América Latina. Formada a cooperativa, o governo repassava o valor para adquirir todo o maquinário e após cinco anos iniciavam a devolução do investimento.

O governo fomentou entre os anos de 2004 a 2006 a criação de mais de 1.000 (um mil) cooperativas de confecção, todos com capacidade e máquinas para produzir uniformes militares, porém não há mercado para tanto. Na verdade, foi criada uma expectativa nesta população, que necessitava ser readaptada.

Outro fator é que a Venezuela importa praticamente $80 \%$ de tudo o que consome, então há por parte do governo muita vontade de abrir novos mercados e o país ser autossustentável com uma economia local.

Além de nós, havia uma equipe da Nicarágua, do movimento dos Sem-Terra do Brasil, dos médicos de Cuba, as habitações da Colômbia.

Durante nossa ida tivemos audiência com a ministra "Oli” onde todos apresentaram seu trabalho, o país enviava expedições para outros países, para levar o trabalho e para trazer 
muito da experiência, como era o caso da Argentina e neste dia Ugo Chaves reuniu vários países da América, o discurso foi de 3h, e no final chegou até nós onde nos apresentamos.

Reunimos lá com várias costureiras, entre os momentos, o marcante foi um encontro com várias cooperativas em Araranguá, já organizadas com coordenações, motivamos tudo o que podíamos para que construíssem uma cadeia com a cara de seu país. Nenhum de nós falava espanhol, mas no final todos arriscavam algumas palavras.

Fomos até São Cristóvão onde havia uma cooperativa resultado de uma empresa recuperada e agora cooperativa de fiação e tecelagem, com maquinários mais atualizados, o que ajudou a reavaliar o nosso controle de qualidade.

Nesta cooperativa estava sendo instalado um posto de saúde para toda população com médicos cubanos, a cooperativa estava bem inserida na comunidade e nos princípios socialistas.

A visita mais difícil foi aos agricultores de Cabruta no Norte da Venezuela divisa com o Rio Orenoco. Com as chuvas o Rio fica cheio durante cinco meses, quando cessam as chuvas, o Rio libera as margens e então plantam o algodão, são mais de 5 espécies de agrotóxicos aplicados. É uma cidade muito pobre e os agricultores também. O calor de 40 graus e as casas todas cobertas por zinco. Viajamos 6 horas de ida e 6 de volta numa estrada em péssimas condições, acompanhando queimadas, por momentos parecia nosso sertão brasileiro. Reunimos os agricultores, a primeira reação foi medir a produtividade e concluíram que eles produziam mais com a monocultura e agrotóxicos.

$\mathrm{Na}$ verdade, precisaríamos mais tempo para esta contabilidade e convencimento, pois eles não somam os custos com os venenos, a própria perda da saúde, e o que estão fazendo com o Rio jogando todo esse veneno e os recipientes também.

No final reunimos os representantes e o governo, organizamos todo um plano, sobretudo por parte dos tecelões que queriam muito uma política para que o governo subsidie. Propuseram permanecermos lá por alguns meses para um acompanhamento mais contínuo, mas nós por outro lado nos propusemos a voltar, colocamos nossa prioridade com o Brasil e com nossa construção que ainda não está consolidada.

Mesmo em alguns momentos que foram difíceis, sobretudo em Cabruta onde a alimentação foi precária, o local onde dormimos também, foi muito importante para nosso crescimento, marcou todos e, com certeza, voltamos profundamente fortalecidos e mais convictos do quanto é importante o que estamos construindo. 
Agora todos os elos se aprofundaram no plantio, ver o plantio consorciado, as dificuldades dos agricultores, as pragas como o bicudo e a lagarta, mas também o profundo convencimento do plantio agroecológico é uma adesão convicta.

E neste período de 2006, o Paraná através da Maethenus faz o primeiro plantio para a Justa Trama. Estive duas vezes em Maringá, na segunda vez foi em Moreira Salles conversando com agricultores e mulheres costureiras.

Iniciamos 2007 com a produção do algodão de 2006 e desta vez fomos para três toneladas na Adec. Pela primeira vez tecemos a malha e o tecido fora da cadeia das cooperativas, pois a Textilcooper não continuava mais. O dono retomara o prédio, e as máquinas e os trabalhadores se dispersavam. Poucos ficaram com o antigo dono. Loide começa a buscar novas alternativas com muitas dificuldades, pois as dívidas recaem sobre o representante jurídico, no caso, ela.

A malha é um pouco mais encorpada, mas no pré encolhimento ela vem mais clara que nos anos anteriores, é muita malha e a sala da Univens se enche de rolos. Fios para Cordão e parte do tecido mais leve vão para a Fio Nobre. Ampliamos para novos produtos como vestidos, bolsas de tear diferentes, começamos a fazer protótipos de calçados com a cooperativa Renacoop. Temos catálogo com os produtos e em abril de 2007 lançamos nossa página www.justatrama.com.br contatos com França e Espanha, lá se vão nossas peças para o exterior. Foi o ano que atendemos demandas de até 800 camisetas. Isso vai nos animando. $\mathrm{O}$ Paraná colhe 8 toneladas de pluma, e precisamos buscar recursos para que os agricultores não se decepcionem e possam receber logo o valor. Assim como precisamos melhorar nossa comercialização.

O ano de 2007 tem sido o ano mais difícil, sempre tínhamos mais problemas e desafios para enfrentar do que o próprio crescimento que deveríamos conquistar. Eram desafios demais e os recursos com as vendas não voltavam na proporção que tínhamos que repassar a cada elo.

Nossa reunião acontece em Rondônia na cooperativa Açaí no mês de maio de 2007. Nesta reunião estavam além de Dalvani e Farias, Chagas, Idalina, Nelsa, Pedro Jorge, Denise e Mariana da Unisol. Esta reunião marca a visita às presidiárias onde produzem peças com sementes e as beneficiam. Visita aos coletores de sementes à beira dos rios, andamos de barco no Rio Canindé onde assustou a todos as condições como vivem e a falta de segurança nos barcos que encontram redemoinhos nas águas. Além dos trabalhadores que colhem subindo nos pés de Açaí sem nenhuma proteção, sobem de pés descalços e com um machadinho em 
uma das mãos, e descem com o mesmo machadinho e segurando o cacho de Açaí, um pé fino e muito alto. Eles descem deslizando e rapidamente.

Hoje o açaí vem em caminhões para SP e, portanto, bastante desvalorizado.

Muitos trabalham com colares e brincos de sementes como fonte única de renda e por haver muito este trabalho é bastante desvalorizado. É preciso construir o diferencial para poder realmente agregar valor.

Foram realizadas várias oficinas no presídio. As presidiárias nos pediram para serem incluídas neste projeto, pois isso dá uma nova perspectiva de vida, um sentido para que se ocupem enquanto estão no presídio e uma esperança para quando saírem de lá.

Mas ainda em agosto de 2007 em Porto Alegre, realizamos a assembleia da fundação jurídica da Justa Trama, que só passa a ser registrada em 13 de janeiro de 2008.

Todos saímos tranquilos pelos desafios cada vez maiores. Estaremos abrindo uma exceção para a Itália e exportaremos 1 tonelada de fio. Mas a inquietude vem do assunto trazido por Pedro Jorge que informou uma nova lei que está para tramitar, que libera o territorial nacional livre para o plantio de algodão transgênico e só impede esse plantio no território da Amazônia, no norte da Bahia e uma pequena área da Paraíba, isso realmente ameaça todo nosso projeto. Precisamos realmente nos mobilizar, sobretudo na preservação da região nordeste como um todo.

Nossa perspectiva cresce com novos produtos para a Itália, e para uma associação (ONG Tauá) da França, que abre uma bela negociação.

Estamos em 2008, será o ano da ampliação e consolidação. Grandes convites para eventos e colocar toda essa construção para o mundo. Queremos também construir a cadeia das sementes da Amazônia. Por isto estaremos indo em todos os estados fazendo o debate e ajudando a construir.

O estado do Ceará se amplia com mais agricultores são em torno de 300 agricultores, 320 fiadores, 20 tecelagens, 45 costureiras e artesãos. Portanto 735 famílias envolvidas diretamente, sabemos o que estamos construindo e sobretudo com um compromisso direto de construção de outra economia, onde é possível conciliar justiça social com distribuição de renda e preservação do meio ambiente. É possível os trabalhadores se organizarem sem atravessadores que concentram renda, e fazer todo o processo desde o plantio, a industrialização e a comercialização.

É um avanço que aponta crescimento no plantio e em todo o processo. Assim evoluímos: 
Justa trama na Colheita de 2004 - 1,5 toneladas

$$
\begin{aligned}
& 2005-2,5 \text { toneladas } \\
& 2006-3 \text { toneladas } \\
& 2007-8 \text { toneladas } \\
& 2008-10 \text { toneladas }
\end{aligned}
$$

É um projeto onde as energias se somam, muita coragem e mão de obra voluntária. Muitos se somam identificando-se com esse projeto e o crescimento é uma mostra de que estamos no caminho certo. Cada consumidor desta cadeia é um adepto a outro tipo de consumo e outra forma de viver, outros valores e sobretudo é um comprometimento com o planeta, e, portanto, com a vida

O Instituto Ecotece adaptou para o português, no Brasil, o vídeo Fibra Ética: Algodão Orgânico, em parceria com a Ong "Pesticide Action Network - PAN UK". A Instituição esclareceu ainda que a produção de Algodão Orgânico no Brasil precisa ser desenvolvida, o acesso ainda é restrito. Encontrar uma roupa feita com algodão orgânico no mercado brasileiro hoje, é raridade. Por isso, é tão importante o acesso à informação para ampliar a consciência quanto à situação atual.

Os consumidores, ao pressionarem o mercado, tem o poder de mudar essa realidade:

- O Brasil é um dos cinco países que mais utilizam agrotóxicos, no mundo;

- São utilizados 160g de agrotóxicos para produzir algodão suficiente para confeccionar uma camiseta que pesa $250 \mathrm{~g}$;

- 25\% dos inseticidas produzidos no mundo são utilizados na plantação do algodão convencional;

- Um hectare de lavoura de algodão utiliza oito vezes mais agrotóxicos do que um hectare de lavoura de alimentos;

- 1 kg de agrotóxicos contamina 1 bilhão de litros de água;

- $80 \%$ das doenças existentes no mundo resultam da escassez ou da poluição das águas;

- Brasil: $6 \%$ do território mundial; $12 \%$ da água doce do mundo.

É por isso que a Justa Trama é uma proposta de desenvolvimento sustentável, e vem para ajudar a construir esse Brasil que tanto sonhamos.

É um momento de muita avaliação de todo processo de produção, da qualidade de nossos produtos e da necessidade urgente de mudanças e ter inovações mais rápidas.

A Adec tem uma boa colheita, se expande para 9 municípios e agora temos 8 toneladas, somada com as que ainda estão sendo processadas, temos a nossa espera 10 toneladas (só com a Adec). Conseguimos pagar os empréstimos feitos com a Unisol Finanças. 
Mas temos outra que precisamos correr atrás. Na verdade, estamos com o tempo correndo e tudo sendo mais lento do que gostaríamos.

Neste ano de 2008 a Justa Trama é convidada a participar da Terra Madre na Itália. Em setembro acontece a reunião que completa o ciclo de reunir cada vez num estado diferente, para que o elo local se aproprie da Cadeia. É a vez da Fio Nobre em Itajaí. Marca a realidade de uma cidade portuária e cercada pelas águas, é onde temos o melhor espaço de comercialização: o centro público.

Na reunião em Itajaí decidimos dar um grande passo no designer com a empresa exmadame (Ronaldo foi indicado por Tadashi) onde participaram os 3 sócios. É nesta reunião que abrimos contato com a Horizonte Têxtil que fará nossa malha, mas o melhor de tudo é que descobrimos a Coopertextil que fica em Pará de Minas (MG), é uma empresa recuperada e hoje uma cooperativa que faz fio e tecido. Denise, em outubro foi até a cooperativa para contatar e conhecer.

Marca um momento de boas relações internacionais, intensificamos com a Itália, a tonelada de fio vai para Made In Nó. Participar do Terra Madre com mais de 8 mil participantes do mundo todo, todos com produtos naturais e fibras naturais, ficamos na cidade de Biella e o evento em Turim. Os dois dias após o encontro estivemos com Luigi da Libero Mondo, em Novara, BRA onde fica a Libera Mondo, além do encontro com Sabina da Nexus. Abrimos novos negócios de camisas pólo e bolsas com comércio justo (Espanta Passari) na cidade de Gênova. Também reunimos com a FAIR para exportação. Isso tudo acontece de 23 a 29 de outubro de 2008. é neste período que nos apropriamos mais do que é a fiação, tecelagem e confrontamos mais com os custos.

O ano de 2009 inicia recompondo a própria Justa Trama, consolidando os elos que já estão, ou seja: Adec, Fio Nobre, Coop. Açaí e Univens e Coopertextil e será o ano que definitivamente consolidaremos a fiação e a tecelagem.

Do Fórum Social Mundial em Belém participamos de oficinas. Comercializamos e realizamos nossa oficina com a sala cheia. Desta vez com a apresentação do vídeo Coopera Brasil com a apresentação de todos os elos feito da Cadeia.

Esse FSM foi de muita emoção pois foi no de 2005 que nós desafiamos a dar este grande passo e hoje já temos 4 anos, vivendo um momento especial e dizemos ao mundo todo que o mundo que queremos para nós é bem real e está acontecendo aqui e agora. É uma mistura de ecologia + ideologia + economia. E isso é possível mesmo de acontecer. O filme Coopera Brasil - Justa Trama é uma expressão dos sentimentos de cada elo e ao mesmo tempo dos coletivos que deles fazem parte, e que fazem seguir para está grande Trama. 
Ainda o ano de 2009 marca a participação da festa do Comércio Justo na Espanha. Hoje mais que nunca está claro o que é ser parceiro, é ser companheiro de jornada, é partilhar do dia a dia, é construir juntos um projeto, e a parte que cada um entra é diversa e sempre surpreendente, pois não é uma troca, é um completando o outro, com o que tem de melhor. É isso que encontramos nos tantos companheiros de Conosud. Repete-se este sentimento com Nexus na Itália.

Revivemos isso também com a participação do Terra Futura, em Florença, a maior feira do Comércio Justo da Itália. Uma grande banca do empreendimento Made In Nó, com roupas íntimas e parte feitas com nosso fio. Também ao encontrar a FAIR que faz toda a exportação, encontrar Luigi que abriu este caminho também reforça as possibilidades e sonhos. Eleonora empenhada em sua tese escrevendo parte de nossa história e de nossos depoimentos de vida.

Muito caminhamos! A Fio Nobre com projeto da Petrobras vem com sua nova sede, dando um novo fôlego à cooperativa. A Cooperativa Açaí na perspectiva de conquista de seu espaço. A Adec novos equipamentos. Na vila onde está a Univens, surge o Centro Social Nova Geração. Um espaço que abriga desde 2006, crianças da comunidade que não estavam em uma escolinha ou creche pelos valores que teriam que pagar para isso, nosso público são filhos da Univens, e crianças que por diversas situações econômicas ou sociais precisam deste espaço. Em 2009 atende 70 crianças, com uma cooperativa de educadoras organizada. O espaço se amplia para outras atividades como o grupo de mulheres na alimentação, e outras iniciativas com jovens e culturais. Também é um espaço de alfabetização de adultos. Este espaço foi sonhado com nossos parceiros da Conosud, e com Angel Merino que sempre teve vontade de apoiar um trabalho com as crianças ainda quando era prefeito da cidade de San Feliu, e a fomentou em nós essa possibilidade.

Aqui creio que podemos dizer que construir a economia solidária é isso, é o compromisso com uma mudança onde você vive, que traz desenvolvimento na melhoria de vida, mas também nas possibilidades de acesso, para que as pessoas sintam que tem um lugar neste mundo, e que é possível vivermos num mundo melhor, onde os filhos tenham um lugar legal para se prepararem para o presente e para o futuro. Construir para os jovens outra possibilidade e outras perspectivas. Que as mulheres possam dançar, ter alegria de viver e que o mundo não se feche na família ou na não família, mas que existe um mundo mais amplo e que a vida pode ter outras possibilidades.

E com tudo sabemos que este país só mudará com mudanças locais, mas também são necessários ações que apontem para uma visibilidade nacional, por isso a Justa Trama é tão 
especial e importante para nós. Assim se espalhando por todo o Brasil para ser grande e construir de verdade outra economia, com valores que sempre sonhamos, sem patrão, dividindo o ganho de forma equitativa, construindo um comércio justo.

Para continuar a luta que também nos dá um grande impulso, em 2009 fomos selecionados como projeto de TECNOLOGIAS SUSTENTÁVEIS entre os 40 dos 430 projetos de vários países promovido pelo instituto Ethos. E no mesmo ano pela Word Changemakers dos 437 projetos de 55 países ficamos entre os 10 selecionados. O programa Changemakers promove modelos de alto impacto social como soluções para problemas mundiais. A iniciativa proporciona destaque internacional para essas alternativas inovadoras com o objetivo de conseguir ampliar sua escala e inspirar novas práticas. Também em 2009, a Fundação Banco do Brasil selecionou a Justa Trama como uma tecnologia social.

Seguindo os anos de 2010 e 2011, a Justa Trama de fato consolida-se com o quadro de associados de 5 Estados e em 4 regiões do Brasil. Ainda retorna para Espanha nos dois anos, Idalina, para a semana do Comércio Justo sendo que em 2011 também Cris participa apresentando a pesquisa que fez junto a Justa Trama.

No ano de 2011 apresentei a Justa Trama no FIEES no Canadá, onde fomos selecionados e convidados entre os mais de mil empreendimentos da economia solidária do Mundo.

No final de 2011 se afilia a Justa Trama a APOMS que é a Associação de Produtos Orgânicos do Mato Grosso do Sul. Localiza em Pontaporã, no assentamento Itamarati formado por 3 mil famílias assentadas, é o maior assentamento do Brasil, e é plantado o algodão Rubi e Verde, inicia com 7 agricultores plantando em 2011. Agora a Justa Trama está nas 5 regiões do Brasil.

Nos percalços de secas, muitas chuvas, enchentes, vamos construindo essa cadeia que percorre o Brasil. Buscando recursos onde estiverem, que seja com parceiros nacionais como Unisol, FBB, Sebrae ou FLD como internacionais: Nexus, Conosud ou Garraf. Mas sempre fortalecendo cada empreendimento filiado. Em 2012 a Cooperativa Acaí com um projeto para Conosud da Espanha conquista sua própria sede.

Um grande esforço para buscar recursos de impacto para enfrentar a pior seca do Nordeste, ter acompanhamento técnico para os agricultores não desistirem dos plantios do algodão. Bem como estamos no foco de construir a sede própria da Justa Trama. Neste curto tempo, 3 das filiadas conquistaram sede própria: Univens, Fio Nobre e Acaí. A Adec ampliou também. Isso é uma expressão de ousadia e luta permanente, além da importância da integração. As reuniões continuam cada vez em uma das bases da Central. A comercialização 
dos produtos avançou bastante e especialmente com produtos corporativos e em feiras, mas ao mesmo tempo cresce as vendas por internet.

E 2011, Tarso Genro assume como governador do RS e sou convidada a compor o governo do Estado, já que é criada a primeira Secretaria Estadual de Economia Solidária do Brasil, assumo como diretora de Economia Solidária. Esse processo mereceu muita reflexão, para assumir este desafio que ele reflete a representatividade que tem toda essa trajetória. Se em todo tempo questionamos a ausência do Estado. Se já percebemos as tantas mudanças positivas que tem no Brasil desde que assumiu o governo Lula e depois Dilma. Podemos simplesmente ignorar este espaço? Ou devemos levar todo esse acúmulo e fazer política pública com o olhar de quem vem do movimento, o olhar de trabalhador? Sem me afastar da Justa Trama em nenhum momento, e sim acumulando mais responsabilidade, vamos construindo outras cadeias produtivas, e tantas leis, quanto programas que possam dar continuidade e fortaleça esta estratégia de desenvolvimento que é a Economia Solidária. E as conquistas vem.

Esse processo influencia também internamente a Justa Trama que pauta prefeitos e secretários locais, para também interferir nas políticas públicas que beneficiam seus associados, mas se estendem a todas as demais iniciativas.

O ano de 2012 tem marcas fortes como a aprovação da lei das cooperativas que reduz a 7 o número mínimo de pessoas necessárias para formar uma cooperativa. Também a lei do Estado do RS, que isenta de ICMS as cooperativas com faturamento até 360mil anual, e para faturamento maior o índice é muito baixo, e isso beneficia diretamente a Justa Trama, que tem sede em Porto Alegre.

A economia solidária do RS pauta seu fortalecimento com a constituição de 6 cadeias solidárias:

- Cadeia Solidária binacional do pet

- Cadeia solidária das frutas nativas

- Cadeia solidária da lã

- Cadeia solidária do peixe

- Cadeia solidária do osso

- Cadeia solidária das pedras

Em termos de leis podemos destacar onde mais avançamos! DECRETO N ${ }^{\circ}$ 48.688 DE 15.12.2011, regulamentou o Conselho Estadual de Economia Solidária, a partir da Lei nº 10.683, de 20 de outubro de 2010, que instituiu a Política Pública de Fomento à Economia Solidária no RS. 
LEI N. ${ }^{\circ}$ 13.874, DE 28 DE DEZEMBRO DE 2011 (publicada no DOE n. ${ }^{\circ}$ 250, de 29 de dezembro de 2011) institui tributação diferenciada de ICMS para cooperativas.

LEI N. ${ }^{\circ}$ 13.922, DE 17 DE JANEIRO DE 2012 (publicada no DOE nº 013, de 18 de janeiro de 2012) Estabelece a Política Estadual para Compras Governamentais da Agricultura Familiar e Empreendimentos Familiares Rurais e da Economia Popular e Solidária - Compra Coletiva/RS - determina que $30 \%$ das compras públicas de produtos e serviços sejam da economia solidária e da agricultura familiar.

LEI No 12.690, DE 19 DE JULHO DE 2012 Lei federal que dispõe sobre a organização e o funcionamento das Cooperativas de Trabalho; institui o Programa Nacional de Fomento às Cooperativas de Trabalho - PRONACOOP; importante especialmente porque reduz para 7 o número de pessoas para formar uma cooperativa no Brasil.

DECRETO No 50.285 DE 30 DE ABRIL DE 2013 Institui a Política Estadual de Certificação dos Empreendimentos Econômicos Solidários, nos termos do inciso II e parágrafo único do art. 17 da Lei no 13.839, de 5 de dezembro de 2011. Certifica o processo de organização dos empreendimentos, identificando-os, priorizando seu acesso às políticas públicas

DECRETO No 50.459, DE 3 DE JULHO DE 2013 Regulamenta o Programa de Economia Popular e Solidária no âmbito do Estado do Rio Grande do Sul, instituído pela Lei n ${ }^{\circ}$ 13.839, de 5 de dezembro de 2011. Permite o aporte de investimentos direto aos Empreendimentos, possibilita a criação do Fundo Público

Além da estratégia da certificação para dar identidade universal a economia solidária e abrir portas de entrada com critérios regulamentados e as Casas de Economias Solidárias que consolidam como espaços permanentes de comercialização, formação e qualificação da gestão e dos produtos.

Em 2016 criamos o banco comunitário Justa Troca dentro da comunidade. Para fortalecer a organização local e promover desenvolvimento. O banco está inspirado no banco Palmas e nos 113 bancos comunitários do Brasil. Aceito em todos os estabelecimentos locais o JUSTO é nossa moeda.

Acredito profundamente na economia solidária, como uma estratégia de desenvolvimento, ela às vezes se confunde com métodos e ações que fazíamos na JOC. Afinal nosso grande desafio é mudar o mundo atuando e lutando onde estivermos.

Esse texto é um resumo de meu livro: TRAMANDO CERTEZAS E ESPERANÇAS escrito em 2014, pela editora OIKOS. 
No período que segue até 2018, a Justa Trama tem se fortalecido e hoje trabalha com o tingimento natural de suas peças, foi selecionada pela FAO - ONU como a melhor metodologia para enfrentamento da pobreza nos países como Bolívia, Paraguai, Peru. Ampliamos a diversidade de produtos da Justa Trama e a produção da malha listada na sede da Cooperativa.

Avançamos em outro desafio que é a organização dos bancos comunitários com moeda própria. Na sede da Justa Trama, abriga o Banco comunitário Justa Troca com a moeda "Justo", que é aceita em todos os estabelecimentos da comunidade, para promover desenvolvimento local fazendo com que o recurso da comunidade fique na comunidade. $\mathrm{O}$ Banco comunitário pertence a rede de bancos que hoje no Brasil soma-se aos 113 existentes e é inspirado no Banco comunitário Palmas, de Fortaleza.

A Economia Solidária vive depois do golpe de 2016 um período forte de ausência total de políticas públicas e neste sentido está sendo um movimento de grande resistência, buscando todas as formas para continuar gerando renda e promovendo desenvolvimento com distribuição justa de renda, defesa do meio ambiente e justiça social.

\section{REFERÊNCIAS}

AGÊNCIA DE DESENVOLVIMENTO SOLIDÁRIO. Programa de ação integrada para economia solidária e desenvolvimento local: complexos cooperativos. São Paulo: ADS, 2002.

BRASIL. Decreto $\mathrm{n}^{\mathrm{o}}$ 48.688, de 15 de dezembro de 2011. Dispõe sobre a composição, estruturação, competência e funcionamento do Conselho Estadual de Economia Solidária CESOL. Diário Oficial da União, seção 1, Brasília, DF., 2002.

BRASIL. Lei $\mathrm{n}^{\text {o }} 12.690$, de 19 de julho de 2012. Dispõe sobre a organização e o funcionamento das Cooperativas de Trabalho; institui o Programa Nacional de Fomento às Cooperativas de Trabalho... Diário Oficial da União: Seção 1, Brasília, DF, de 20 de junho de 2012.

RIO GRANDE DO SUL. Decreto $\mathrm{n}^{\circ}$ 50.285, de 30 de abril de 2013. Institui a Política Estadual de Certificação dos Empreendimentos Econômicos Solidários, nos termos do inciso II e parágrafo único do art. 17 da Lei $\mathrm{n}^{\circ} 13.839$, de 5 de dezembro de 2011 . DOE, $\mathrm{n}^{\circ}$ 083, de 02 de maio de 2013.

RIO GRANDE DO SUL. Decreto $n^{\circ} 50.459$, de 3 de julho de 2013. Regulamenta o Programa de Economia Popular e Solidária no âmbito do Estado do Rio Grande do Sul, instituído pela Lei ${ }^{\circ} 13.839$, de 5 de dezembro de 2011. DOE, nº 127, de 04 de julho de 2013. 
RIO GRANDE DO SUL. Lei $\mathrm{n}^{\circ} 13.874$, de 28 de dezembro de 2011. Introduz modificações na Lei n. ${ }^{\circ} 8.820$, de 27 de janeiro de 1989, que institui o Imposto sobre Operações Relativas à Circulação de Mercadorias... DOE, nº 250, de 29 de dezembro de 2011.

RIO GRANDE DO SUL. Lei ${ }^{\circ}$ 13.922, de 17 de janeiro de 2012. Estabelece a Política Estadual para Compras Governamentais da Agricultura Familiar e Empreendimentos Familiares Rurais e da Economia Popular e Solidária. DOE, nº 013, de 18 de janeiro de 2012. 